\title{
Correction to: Boundedness of spectral multipliers of generalized Laplacians on compact manifolds with boundary
}

\author{
Mayukh Mukherjee ${ }^{1,2}$
}

Published online: 9 May 2018

The Author(s) 2018, corrected publication 2019

\section{Correction to: Math. Z. https://doi.org/10.1007/s00209-017-1986-9}

In the original publication, the corresponding author's affiliation was missed to include the 'Max Planck' institution details.

The correct affiliation should read as,

'Max Planck Institute for Mathematics, Bonn'

Present Address:

The Technion, Haifa, Israel

The original article has been corrected.

Open Access This article is distributed under the terms of the Creative Commons Attribution 4.0 International License (http://creativecommons.org/licenses/by/4.0/), which permits unrestricted use, distribution, and reproduction in any medium, provided you give appropriate credit to the original author(s) and the source, provide a link to the Creative Commons license, and indicate if changes were made.

The original article can be found online at https://doi.org/10.1007/s00209-017-1986-9.

$凶$ Mayukh Mukherjee

mathmukherjee@gmail.com

1 Max Planck Institute for Mathematics, Bonn, Germany

2 Present Address: The Technion, Haifa, Israel 